\title{
A Hidden Markov Model of Customer Relationship Dynamics in Retailing Industry
}

\author{
Gang $\mathrm{Li}^{1,3}$, Chunqing $\mathrm{Li}^{2,3}$, and WeiFeng $\mathrm{Jia}^{3}$ \\ 1 College of Automation, Northwestern Polytechnic University, Xi' an \\ Shaanxi 710072, $\lg 21 \mathrm{c} @ 163 . c o m$ \\ 2 School of Economics and Management, Tsinghua University, Beijing \\ 100084, lichq@em.tsinghua.edu.cn \\ 3 School of Economics \& Management, Xi'an Shaanxi Institute of \\ Technology, Xi'an 710032, thisisjia@163.com
}

\begin{abstract}
There are many types of relationship encounter between customers and retailing industry such as advertisement, service encounter, targeted marketing activities, price and display promotions, these customer- retailing industry encounter may have some enduring or immediate impact on customer's buying behavior. In the sequence of customer's buying behavior and relationship encounter, the customer may be in some state latently which has different likelihood to choose and shift between them. However, the researcher can not observe the actual state directly except observes the buying behavior.

We apply Netzer [1] approach to evaluate of the effectiveness of customer-brand encounters on the dynamics of customer relationships and the subsequent buying behavior, we construct a hidden Markov model in which the Markovian states are a finite set of relation states, the number of states is determined by Bayes factor with validation log-likelihood and the log marginal density measures. The transitions between the states are determined by the history of interactions between the customers and the brand. The probability of a dichotomous choice is determined by the encounters that have an immediate effect on the customer's choice. The individual-level parameters are estimated using a Markov Chain Monte Carlo hierarchal Bayes procedure [2]. We calibrate the proposed model using demographic data, as well as using longitudinal purchasing data provided by shopping mall. We use some other data to assess the prediction ability of the HMM.

This empirical application demonstrates the value of the proposed model in understanding the dynamics of customer-company relationships and
\end{abstract}

Please use the following format when citing this chapter:

Li, G., Li, C., Jia, W., 2006, in International Federation for Information Processing, Volume 205, Rescarch and Practical Issucs of Enterprise Information Systems, cds. Tjoa, A.M., Xu, L., Chaudhry, S., (Boston:Springer), pp.633-634. 
predicting purchase behavior. Using the proposed model, we are able to probabilistically classify the customer base into several relationship states [3], and estimate the marginal impact of customer-company interactions on moving the customer between these states. It is important to find which is the strongest marketing activity, which pushing the customer to higher state that has bigger probability to choose.

In order to balance the expenditure, marketing activities should be targeted on those whose likelihood is maximal [4]. The proposed model could be used to estimate the customer's relationship state based on its demographic data and transaction record. Compared with the customer segmentation on observed behavior, we can see latent states customer segmentation can increase the amount of purchase much more.

\section{Acknowledgements}

This research is supported by National Natural Science Foundation of China $(70572009,70302001)$, Postdoctoral Science Foundation of China (2005037374) and the Education Department of Shaanxi Province (05JK046).

\section{References}

1. O. Netzer, J.M. Lattin, V. Srinivasan, A Hidden Markov Model of Customer Relationship Dynamics, Research Paper No. 1904, pp. 10-15.

2. W.R. Gilks, S. Richhardson, and D.J. Spiegelhalter, Markov Chain Monte Carlo in Practice (Chapman \& Hall Press, 1996) pp. 303-315

3. R.I. Andrews and I.S. Currim, A comparison of Segment Retension Criteria for Finite Mixture Models, Journal of Marketing Research, 39(May), 235-243 (2003).

4. J.D. Soukup, A Markov Analysis of Fund-Raising Alternatives, Journal of Marketing Research 20(August), 314-319 (1983). 